\title{
CONE) (OES
}

CIÊNCIA E TECNOLOGIA

\section{AS FACES DA SECA: AS TRANSFORMAÇÕES SOCIOESPACIAIS DAS GRANDES SECAS NO CEARÁ (1979-83 E 2011-16)}

\author{
DANIELLE RODRIGUES DA SILVA ${ }^{1}$, JACKSON ARAUJO DE SOUSA $^{1}$ \\ ${ }^{1}$ Instituto Federal de Educação, Ciência e Tecnologia do Ceará (IFCE) \\ <danigeoufc@gmail.com>,<sousa.j.a.ifce@gmail.com> \\ DOI: 10.21439/conexoes.v13i5.1869
}

\begin{abstract}
Resumo. O Estado do Ceará vivenciou, historicamente, períodos de grandes secas que foram responsáveis pela perda da produção, queda de produtividade, dificuldade de acesso à água, aumento de doenças e até mesmo mortes. O cenário de calamidade pública e aparente destruição que constitui a paisagem nesse período vem passando por transformações que possibilitaram ao homem do campo, estabelecer uma relação diferente com esse fenômeno. Discorrendo sobre as consequências desse processo, em períodos distintos, esse artigo visa analisar as principais transformações socioespaciais das grandes secas de 1979-83 e 2011-16, no estado do Ceará. Para sua realização, contou-se com o levantamento bibliográfico, análise de dados secundários do Ministério do Desenvolvimento Social e, sistematização dos mesmos. Comparativamente, concluiu-se que os instrumentos técnicos, desenvolvidos tanto pelo Governo como pelos movimentos e organizações sociais, tais como, cisternas de placa, barreiros, barragens, mandalas, dentre outros, provocaram as maiores transformações na forma de lidar com a seca no Ceará, no segundo período, permitindo que cada vez mais o homem possa permanecer e viver no campo mesmo em tempo de escassez.
\end{abstract}

Palavras-chave: Ceará. Seca. Transformações socioespaciais

\section{THE FACES OF DRY: THE SOCIO-SPACE TRANSFORMATIONS OF THE GREAT DRYS IN CEARÁ (1979-83 AND 2011-16)}

\begin{abstract}
The state of Ceará has historically experienced periods of great droughts that were responsible for the loss of production, reduced productivity, difficulty in accessing water, increased disease and even death. The scenario of public calamity and apparent destruction that constitutes the landscape in this period has been undergoing transformations that enabled the countryman to establish a different relationship with this phenomenon. Discussing the consequences of this process in different periods, this article aims to analyze the main socio-spatial transformations of the great droughts of 1979-83 and 2011-16, in the state of Ceará. For its accomplishment, it was counted on the bibliographic survey, analysis of secondary data of the Ministry of Social Development and its systematization. Comparatively, it was concluded that the technical instruments developed by both the Government and social movements and organizations, such as plate cisterns, barriers, dams, mandalas, among others, caused the biggest changes in the way to deal with drought in Ceará., in the second period, allowing more and more man to stay and live in the countryside even in times of scarcity.
\end{abstract}

Keywords: Synthetic dyes. Work. Kinetic. Electricity. Neural network 


\section{INTRODUÇÃO}

O Estado do Ceará tem sido, historicamente, marcado pela ocorrência de secas periódicas, que de um lado devastam a paisagem, impactam a economia e desarticulam processos produtivos, e por outro, afetam a capacidade de reprodução social, sobretudo da população camponesa, que localiza-se geograficamente em áreas de difícil acesso, com geologia de embasamento cristalino, sem infraestrutura hídrica adequada e suficiente para garantir a satisfação das necessidades em períodos de escassez.

No século passado, até fins dos anos de 1980, os períodos de escassez hídrica, popularmente difundido como seca, traziam consigo cenários desoladores, com perda da plantação, perda da produção, aumento da migração e inúmeras mortes. Sobre essas últimas, o livro Genocídio no Nordeste, publicado em 1989, revela inúmeras ocorrências de mortes, principalmente de crianças, que à época, não puderam lidar com os reflexos da escassez hídrica, sendo dessa forma, atingidas pelas doenças oportunistas, ingestão de água com péssimas condições de salubridades, disenterias, desidratação, dentre outras associadas ao período.

Destarte frisar, que as estratégias de combate à seca e políticas implementadas no estado do Ceará à época, não eram eficientes para garantir acesso à água para a população do campo. Fatores ambientais, políticos, econômicos e sociais estão todos envoltos nessa trama de falta de resolutividade para esses grupos sociais.

A partir de meados da década de 1990, observase no Estado, algumas estratégias políticas, mas também, populares de desenvolvimento de tecnologias de convivência com o semiárido, e consequentemente, com o fenômeno das secas. Decerto, a evolução do meio técnico, científico e informacional (SANTOS, 2006), contribuiu sobremaneira para o desenvolvimento e disseminação de inúmeros instrumentos de convivência com a escassez de água por meio do seu armazenamento no Estado do Ceará. Certamente esse processo, teve influência sobre os cenários que se estabeleceram nos períodos de estiagem a posteriori.

Diante dessa realidade, nossa inquietação para o presente artigo é: Quais as principais transformações socioespaciais ocorridas entre as grandes secas (1979-83 e 2011-2016) no Estado do Ceará e seus reflexos na forma de lidar com os períodos de estiagem no Estado?

\section{OBJETIVOS}

\subsection{Objetivo Geral}

Analisar as principais transformações socioespaciais das secas de 1979-83 e 2011-16, no Estado do Ceará.

\subsection{Objetivos específicos}

- Levantar os principais impactos socioespaciais provocados pelas secas (1979-83 e 2011-16);

- Discutir as principais mudanças ocorridas no Ceará nas grandes secas (1979-83 e 2011-16);
- Compreender as nuances do fenômeno da seca no Estado do Ceará;

\section{FUNDAMENTAÇÃO}

\subsection{As faces da Seca}

A compreensão da seca, requer o entendimento dos diversos elementos que a compõe. A priori, a seca é associada a uma variante climática: a irregularidade pluviométrica, é, portanto, inexorável (CASTRO, 1992). Desse ponto de vista, essa só se daria nos anos em que a quantidade de chuvas fica abaixo da média pluviométrica anual. No entanto, associada a outros elementos de natureza econômica, política e social, a seca no Nordeste tem assumido uma complexidade que deve ser considerada nas análises, pois o Nordeste é filho das secas (ALBUQUERQUE JÚNIOR, 2011) e essa temática tem monopolizada as discussões nesta região brasileira (op. cit., 2018). A seca tem servido de argumento para a legitimação política regional, através de um discurso da seca alavancado pela elite política nordestina, disseminando o chamado mito da necessidade (CASTRO, 1992). Em complementação a essa abordagem da seca, aparece ainda sua valorização sob o ângulo cultural, sendo divulgada nas produções literárias, musicais, fílmicas e das artes plásticas e etc. (ALBUQUERQUE JÚNIOR, 2011). Portanto, para além de uma discussão meramente geoambiental, deve-se considerar os fatores de cunho social. Essa reflexão pode se iniciar a partir da indagação de Tomaz Pompeu Sobrinho apud Neves (2015): “o que nos importa uma seca no deserto?".

De fato, a discussão sobre escassez hídrica em um espaço inabitado pouco nos importa, cabendo talvez seu estudo ao campo das ciências naturais e da terra. Entretanto, o estado do Ceará, que possui a maior parte de seu território localizado no semiárido brasileiro, tem uma população significativa de 8.452.381 habitantes (IBGE, 2010), o que equivale a aproximadamente $4,4 \%$ da população brasileira. Logo, a seca tem caráter social. Como pontua Neves (2015):

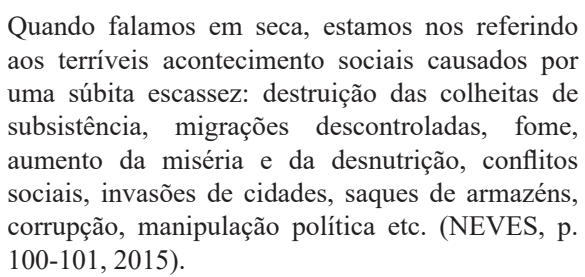

A história das secas é marcada por fenômenos sociais, deliberados ou não pelo Estado: Campos de concentração, frentes de serviço, migrações, paternalismo etc. Dois fatores foram elencados por Neves (2015) como definidores de uma nova compreensão das secas no Ceará, tendo como marco de tempo a seca de 1877-79. O primeiro foi a lei de terras de 1850 que instituiu a posse da terra apenas pela compra, aliado a agricultura mercantil que privilegiava um excedente econômico, impossibilitando a ocupação das áreas mais úmidas, chamada de brejos por Ab'saber (1999) ${ }^{1}$, pelas populações que

$1 \mathrm{Na}$ cultura popular dos sertões é costume reconhecer-se por brejo qualquer subsetor mais úmido existente no interior do domínio semi-árido; isto é, 
sofriam com a seca, e ainda, retirando das tribos indígenas o controle de suas terras; o segundo, foi a Guerra de Secessão no EUA, que estimulou a cultura algodoeira no Ceará e aumentou subitamente os preços do produto no mercado internacional (o fim da guerra em 1865 vai também significar o declínio da cultura no estado). Ainda segundo o autor,

\begin{abstract}
Neste momento, a irregularidade de chuvas deixa de ser "apenas" uma questão climática para se tornar uma questão social, que a todos afeta e que o Estado brasileiro não poderá mais ignorar. De fato, inaugura-se neste instante a seca tal qual a entendemos hoje: miséria, fome, destruição da produção, dispersão da mão de obra, migrações, invasões às cidades, corrupção, saques... (NEVES, 2015, p. 80).
\end{abstract}

Vários acontecimentos ocorreram nesse período no Nordeste de forma geral, e no Ceará, particularmente, que o caracterizam como importantes para a história das secas. Segundo Cerqueira (1989),

\begin{abstract}
A política do Estado em relação à seca, num primeiro momento, foi perpassada pelos interesses da oligarquia, que, ao deter o monopólio da terra e os vários mecanismos de reprodução do Nordeste seco, pode também se apropriar do poder do Estado, em especial dos aparelhos estatais voltados para a questão. Num segundo momento, após a criação da SUDENE - e mais precisamente, depois do golpe de 1964 - os interesses em jogo correspondem a uma simbiose entre capital nacional hegemônico, cada vez mais monopolista, e as oligarquias, resultando na modernização conservadora da agricultura, que sem alteração das estruturas, cresce excluindo. Toda a política em torno da seca não é outra coisa senão o alimentar constante destas estruturas de poder que conformam a indústria da seca (CERQUEIRA, 1989, p. 52).
\end{abstract}

De acordo com o exposto vê-se que, no Ceará, o lidar com a seca para as comunidades, esteve historicamente associado ao nível de dependência que as mesmas possuíam e possuem em relação aos grupos oligárquicos do Estado. Essa dependência se concretiza, por exemplo, nos postos de trabalho nas frentes de serviço, na inclusão nos cadastros de políticas compensatórias que foram implementadas no Estado, no acesso aos recursos hídrico que foram instalados em propriedade particulares com o dinheiro do Governo, dentre outros.

É nesse aspecto, que as duas grandes secas ocorridas no Ceará, apresentam mudanças significativas nos reflexos desse processo na vida da população cearense. E é sobre esses aspectos que pretendemos discutir neste trabalho.

\section{METODOLOGIA}

A realização deste trabalho se amparou no desenvolvimento de uma pesquisa de natureza qualitativa, calcada na revisão da literatura e levantamento de dados. Inicialmente realizou-se um levantamento bibliográfico sobre

qualquer porção de terreno dotada de maior umidade, solos de matas e filetes d'água perenes ou subperenes, onde é possível produzir quase todos os alimentos e frutas peculiares aos trópicos úmidos (AB'SABER, 1999, p. 17). as grandes secas ocorridas no estado do Ceará, com foco nas secas de 1979-83 e 2011-16, sobre as condições geoambientais do estado do Ceará, sobre as políticas de desenvolvimento dos recursos hídricos no estado e os reflexos desse processo na organização espacial do Estado. Para estes feitos, nos baseamos principalmente em Neves (2015), Pontes (2010), CPT, IBASE, CEPAC (1989), Cerqueira (1989), Ab'Saber (1999), Cavalcante e Pessoa (2002) e Vianna (2011).

Parte dos dados que subsidiaram esse trabalho foram coletadas no SIG Web do Ministério do Desenvolvimento Social (MDS, 2018) em parceria com a Empresa Brasileira de Pesquisa Agropecuária (Embrapa). Nele foram encontradas as informações sobre o número de cisternas de placas e de outras tecnologias sociais utilizadas no estado do Ceará, que utilização na elaboração do mapa. Também foram utilizados dados sobre divisão de área por estabelecimento rural do livro Genocídio do Nordeste, baseado no IBGE.

A partir desses dados e informações, produziu-se, por meio da utilização do QGIS 2.18 Las Palmas, o mapa das tecnologias sociais, utilizado para o debate sobre as modificações socioespaciais no Ceará. Por fim, procedeuse a análise dos dados e informações para compor o debate proposto.

\section{RESULTADOS E DISCUSSÃO}

De acordo com a literatura produzida, a seca de 1979 a 1983 foi um marco na compreensão desse fenômeno no século XX, assim como foi a seca de 1877-1879 no século XIX. Foi a pior seca do século, dizem os mais velhos (CPT; CEPAC; IBASE, 1989, p. 7). Segundo depoimento coletado no município de Tauá - CE por Cavalcante e Pessoa (2002), essa seca foi "em matéria de carência d'água, [...] a pior de todas" (p. 22).

A pesquisa realizada pela CPT, CEPAC e IBASE (1989) constata a ocorrência de 700.000 mortes na área afetada pela seca no Nordeste brasileiro nesse período. Em virtude desse número, utiliza-se o termo genocídio, que inclusive dá nome ao livro de divulgação da pesquisa: O genocídio do Nordeste (1979-1983):

Quando falamos de genocídio, não colocamos mais
a seca como responsável pelas mortes. Afirmamos
que houve uma intenção no crime cometido,
intenção de autores humanos que devem ser
responsabilizados pelo resultado de suas atitudes e
de suas omissões (RECH, 1989, p. 21).

Nesse período foram registrados alistamentos em frentes de serviço e/ou emergência ${ }^{2}$. No caso do Estado do Ceará, foram mobilizados em 1979, 191.940 trabalhadores, sendo 166.655 pela Secretaria de Agricultura, 18.352 pelo Departamento Nacional de Obras Contra as Secas (DNOCS) e 6.933 pelo $1^{\circ}$ Grupamento de Engenharia ( $1^{\circ}$ GPT E) (CAVALCANTE; PESSOA, 2002).

O estudo feito pela Fundação Joaquim Nabuco (ibid)

2 A diferença é que nas frentes de serviço os flagelados trabalhavam nas grandes propriedades, em obras que os latifundiários definiam: açudes, barragens, cercas, destocamento etc, enquanto que nas frentes de emergência os alistados eram aproveitados em obras públicas (SOUZA, 1989, p. 102) 
teve como foco temporal os dois primeiros anos da referida seca (1979-1983), que aqui buscamos compreender. Ainda assim, serve como fundamentação teórica e fonte de dados que fortalecem nossa discussão.

No Nordeste, no ano de 1979, segundo os autores foram mobilizados 432.057 trabalhadores. Em 1983, cinco anos depois, houve um salto para 2.700.000 trabalhadores mobilizados (CPT; CEPAC; IBASE, 2002). Considerando que no período analisado por Cavalcante e Pessoa (2002), apenas um componente da família, e na grande parte homens, principalmente no Ceará, poderia se alistar nas frentes de serviço, a situação de sobrevivência da família se torna penosa, tendo em vista toda a estrutura agrária que envolve o contexto da região semiárida naquele período e que tem paralelo ainda hoje. Ainda assim, as frentes eram fator impactante frente a decisão de não emigrar. Mesmo sendo uma política precária, muito na perspectiva de dar um último suspiro a quem está morrendo, ela permitia em muitos casos a permanência no local de origem: "Graças a Deus, o Governo mandou essa Emergência e não precisou nós arribar daqui”, em depoimento a Cavalcante e Pessoa (2002, p. 42)

Essa estrutura é particularmente perversa, não restrita ao Nordeste, como fala Oliveira (2001): “o traço essencial da estrutura fundiária brasileira, é portanto, o caráter concentrado da terra" (p. 29). Segundo Oliveira (2001),

\begin{abstract}
[...] o Nordeste que tem uma estrutura fundiária herdada do período colonial, apresentava em 1985 uma elevadíssima participação dos estabelecimentos de menos de 10 ha. Estes representavam mais de $70 \%$ do total, ficando, entretanto, com apenas pouco mais de $5 \%$ da área total da região. Enquanto os latifúndios com mais de 1000 hectares, que representavam tão-somente $0,4 \%$ dos estabelecimentos, ficavam com mais de $32 \%$ da área total (OLIVEIRA, 2001, p. 32).
\end{abstract}

De forma mais acurada o MIRAD-INCRA apud Rech (1989) detalhou a distribuição das terras por propriedades rurais no Nordeste do Brasil, considerando o total de área cadastrada pelo INCRA no ano de 1978 (Tabela 1).

Tabela 1: Distribuição de área por estabelecimento rural no Nordeste para o ano de 1978.

\begin{tabular}{|c|c|}
\hline Estabelecimento & Área (ha) \\
\hline Minifúndio & $14.231 .327,1$ \\
\hline $\begin{array}{c}\text { Empresa rural } \\
\text { Latifúndio por } \\
\text { exploração }\end{array}$ & $3.048 .345,0$ \\
\hline $\begin{array}{c}\text { Latifúndio por } \\
\text { dimensão }\end{array}$ & $9.343 .627,1$ \\
\hline Outros & $5.428 .159,4$ \\
\hline Total & $\mathbf{1 0 3 . 7 6 1 . 1 8 5 , 2}$ \\
\hline
\end{tabular}

Fonte: MIRAD-INCRA apud Rech (1989).

Podemos perceber assim, a verdadeira "aventura" que era construir uma vida e dar subsídios a própria família. Os sertanejos enfrentam naquele período um contexto social que não os favorecia e que em nada contribuía para sua permanência. Não é a escassez hídrica, variante climática, a determinante que os afastava da convivência no espaço semiárido, mas necessariamente uma plêiade de fatores, essencialmente de cunho humano, que convergem para tornar o sertão cearense desproporcional à permanência. $\mathrm{O}$ sertão vivencia, para usar termos de Ab'saber (1999), uma geografia humana sofrida.

Na seca de 2011-2016, decorrente de um largo processo de mudança na forma de entender e compreender a seca ${ }^{3}$, o cenário foi outro. Mas como isso foi possível se este período no Estado do Ceará foi o "mais severo de seca dos últimos 100 anos" (CORTEZ; LIMA; SAKAMOTO, 2017, p. 84)?

A atuação dos movimentos sociais, ONGs e articulações nas últimas décadas têm gerado novos cenários, distintos dos já costumeiros no semiárido. A atuação da Articulação do Semiárido Brasileiro (ASA) tem sido salutar nessa dinâmica, principalmente com o desenvolvimento de políticas públicas, com destaque ao programa Um Milhão de Cisternas Rurais (P1MC).

Como forma de driblar as perspectivas negativas herdadas dos padrões históricos de exploração na região semiárida, metodologias participativas de avanço na qualidade de vida das comunidades rurais, têm se tornado cada vez mais constantes nas pautas do movimento social organizado e do próprio governo federal (VIANNA, 2015, p. 423).

Novas perspectivas de mudanças têm sido geradas a partir de políticas que emergiram da luta de movimentos sociais e que proporcionam ao homem sertanejo uma perspectiva de que pode permanecer no seu espaço de vida, sem sofrer maiores consequências às custas de uma pretensa natureza determinista.

A figura 1 apresenta a distribuição espacial das cisternas de placas para consumo humano ${ }^{4}$. Nesta, podemos perceber que a maior concentração de cisternas se encontra na área central do Estado do Ceará.
3 Principalmente com a institucionalização da Articulação do Semiárido Brasileiro (ASA) em 1999. O fundamento principal é o compromisso com as necessidades e interesses das populações locais, especialmente os agricultores familiares, estimulando o uso sustentável e recomposição dos recursos naturais do semiárido, buscando quebrar o monopólio do acesso à terra, água e outros modos de produção (PONTES, 2010, p. 104).

4 Esses dados se referem ao número de cisternas por município implantadas através do Programa Nacional de Apoio à Captação de Água de Chuva e Outras Tecnologias Sociais (Programa Cisterna), diz o MDS. Ainda fazem parte do programa as cisternas para produção e para as escolas que não foram referenciadas na Figura 1. 
Figura 1: Cisternas e outras tecnologias sociais de acesso a água para uso familiar no Estado do Ceará.

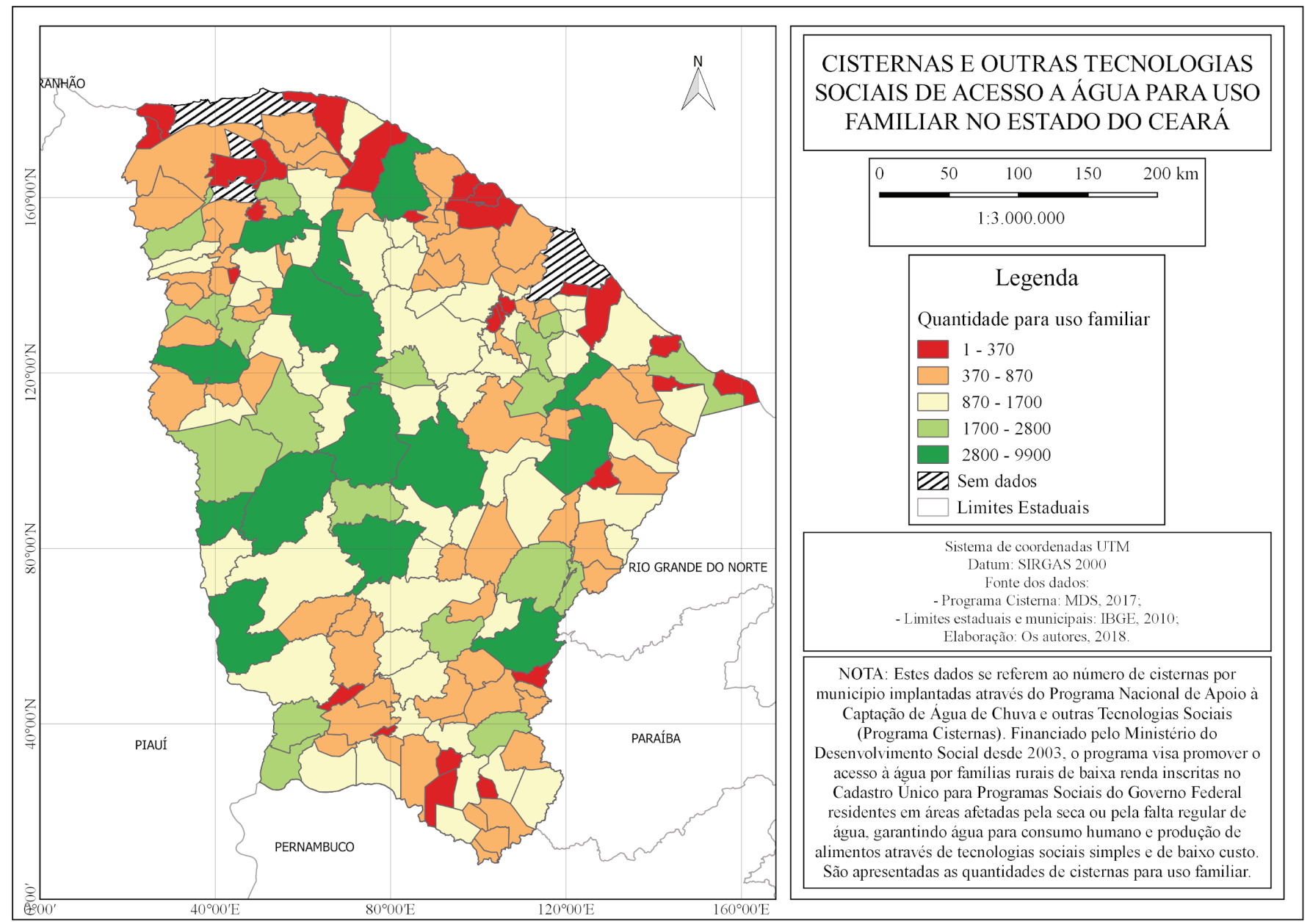

Fonte: Ministério do Desenvolvimento Social, 2017. Elaboração: Jackson Sousa, 2018

É necessário salientar o papel que as políticas de transferência de renda têm na decisão de migrar. A pesquisa desenvolvida por Ojima, Costa e Calixta (2014), teve como recorte espacial, a região do semiárido setentrional, que compreende os municípios do semiárido nos estados do Piauí, Ceará, Rio Grande do Norte, Paraíba, Pernambuco e Alagoas e ainda o recorte temporal de 2007-2010, mas para fins de compreensão da dinâmica que envolve o Estado do Ceará é pertinente suas colocações, apesar de este ter suas dinâmicas particulares. Diz ele,

$[\ldots .$.$] como apontado pela literatura, [\ldots]$ os benefícios sociais podem ter efeito tanto de atrair imigrantes (sobretudo os migrantes de retorno no caso do semiárido) como também de reduzir o ímpeto emigratório uma vez que é reduzida a proporção de emigrantes que recebem benefícios sociais. (p. $158)$.

Nesse sentido, a decisão de emigrar para outra região, ou mesmo para a capital, Fortaleza, na seca de 1979-83 era muito mais propensa por conta da inexistência de benefícios sociais, realidade que tem se alterado na seca de 2011-16 com a instituição destes, principalmente o bolsa família.

Ojima, Costa e Calixta (2014) ainda salientam o papel do
INSS no que se refere a decisão de não migrar, principalmente para outras regiões do país, nesse caso, por conta de uma certa independência em relação ao mercado de trabalho das pessoas beneficiárias.

Os autores supracitados, analisando a relação dos municípios que decretaram Situação de Emergência (SE) ou Estado de Calamidade Pública (ECP) à proporção de emigrantes, falam que, "o fato de não haver uma proporção mais expressiva de emigrantes oriundos de municípios que declaram SE e ECP pode refletir formas de convivência com a seca por parte da população" (p. 158), confirmando a importância das políticas de convivência com o semiárido.

Assim eles concluem que,

$$
\begin{aligned}
& \text { [...] o fato do indivíduo residir ou não em município } \\
& \text { do semiárido setentrional que tenha decretado } \\
& \text { Situação de Emergência ou Estado de Calamidade } \\
& \text { Pública devido à seca não se constitui como um } \\
& \text { fator estatisticamente significante para explicar o } \\
& \text { motivo da emigração dessa região. Neste sentido, } \\
& \text { confirma-se o que a literatura discute sobre a } \\
& \text { dificuldade de se encontrar uma relação com } \\
& \text { fatores climáticos e ambientais. De fato, o que } \\
& \text { pudemos perceber é que fatores socioeconômicos } \\
& \text { associados ao recebimento de benefícios de } \\
& \text { programas sociais possuem muito mais peso na } \\
& \text { emigração dos indivíduos dessa região. [...] Assim, }
\end{aligned}
$$


seria correto afirmar que as políticas sociais, de alguma forma, se apresentam como fatores de retenção da população no semiárido setentrional (OJIMA; COSTA; CALIXTA, 2014, p. 163-164).

Podemos destacar ainda as transformações, aquisição e difusão dos meios técnicos que foram capazes de fortalecer as práticas da agricultura familiar (barragens subterrâneas, produção agroecológica, mandalas, etc.) que no semiárido tem tido papel salutar na permanência do homem no campo e na sua capacidade de resistência nos períodos de escassez hídrica .

\section{CONSIDERAÇÕES FINAIS}

Se nós considerarmos que apenas o clima é determinante para o contexto social, político e econômico do semiárido, estaríamos supondo que os acontecimentos sociais da seca de 2011-16 seriam mais graves que na seca de 1979-83, já que a primeira é considerada a seca mais severa dos últimos 100 anos. Tomando como verdade esse fato, o contexto de mortes, migrações, fome, miséria seria tanto mais latente, o que não procede. Vários programas e projetos direcionados para a população mais pobre do semiárido atuaram no sentido de alteração do contexto social. Além disso, o desenvolvimento das políticas hídricas no Ceará, a mudança paradigmática da convivência com a seca, apesar dos conflitos que o cerceia, também contribuíram para que novos cenários se apresentassem nas secas mais recentes.

Nem sempre, políticas para o semiárido tiveram um papel de mudança, caso exemplar da política de açudagem, a chamada "solução hidráulica", que culminou em aprofundar a disparidade social e os vínculos de dependência na região Nordeste como um todo, e no Ceará em particular. Atualmente, políticas hídricas ainda são desenvolvidas.

O caso da transposição do São Francisco é emblemático no semiárido, e no Ceará. O Cinturão das Águas tem sido alvo de ferrenhas críticas, muito por conta de ser direcionado não ao pequeno agricultor - aliás, é inclusive, motivo de desapropriação - mas ao grande produtor, que tem foco na exportação, e aos complexos industriais. Se antes a açudagem privilegiava o latifundiário/coronel, hoje está direcionado aos complexos agroindustriais e ao agrohidronegócio.

Das leituras e reflexões realizadas, reafirmamos que o comparativo dessas duas grandes secas no Ceará, revela que os instrumentos técnicos desenvolvidos tanto pelo Governo, com a política de açudagem por exemplo, como pelos movimentos e organismos sociais, com as cisternas de placas, cisternas calçadão, barragens de pequeno porte, barragens subterrâneas, mandalas, barreiros, transferências de renda, entre outros, a partir da década de 1990, provocaram as maiores transformações na forma de lidar com secas no Ceará, permitindo que cada vez mais o homem possa permanecer, e mais que isso, viver no campo mesmo em tempo de escassez.

Decerto, a mudança paradigmática - de combate à seca para a convivência com a seca - muito contribuiu para uma releitura da seca no Estado do Ceará e o estabelecimento de inúmeras práticas sociais que foram incorporadas tanto pelas populações do campo como pelos empreendimentos comerciais.

\section{REFERÊNCIAS}

AB'SABER, Aziz Nacib. Sertões e sertanejos: uma geografia humana sofrida. Estudos Avançados, São Paulo, v. 13, n. 36, p. 07-59, mai/ago, 1999.

ALBUQUERQUE JÚNIOR, Durval Muniz de. A invenção do Nordeste e outras artes. 5. ed. São Paulo: Cortez, 2011.

CASTRO, Iná Elias de. O mito da necessidade: discurso e prática do regionalismo nordestino. Rio de Janeiro: Bertrand Brasil, 1992.

CAVALCANTE, Clóvis de Vasconcelos; PESSOA, Dirceu Murilo. A Seca de 1979-1980: uma avaliação pela Fundação Joaquim Nabuco. - Fortaleza: Banco do Nordeste; Recife: Fundação Joaquim Nabuco, 2002.

CERQUEIRA, Paulo Cezar Lisboa. A seca no contexto social do Nordeste In: CPT. CEPAC. IBASE. O genocídio do Nordeste (1979-1983). São Paulo: Mandacaru, p. 31-72, 1989.

CORTEZ, Helder dos Santos; LIMA, Gianni Peixoto de; SAKAMOTO, Meiry Sayuri. A seca 2010-2016 e as medidas do Estado do Ceará para mitigar seus efeitos. Parc. Estrat, Brasília-DF, v. 22, n. 44, p. 83-118, jan-jun, 2017.

CPT. CEPAC. IBASE. O genocídio do Nordeste (1979-1983). São Paulo: Mandacaru, 1989.

INSTITUTO BRASILEIRO DE GEOGRAFIA E ESTATÍSTICA - IBGE. Censo demográfico, 2010. Disponível em: $\quad<$ https://sidra.ibge.gov.br/pesquisa/censo-demografico/ demografico-2010/inicial > . Acesso em: 22 de jun de 2018

MINISTÉRIO DO DESENVOLVIMENTO SOCIAL (MDS). Inclusão produtiva no seu município (GeoWeb MDS). Disponível em: <http://mapas.cnpm.embrapa.br/ mds/?layers=1> Acesso em: 24 de jun. 2018.

NEVES, Frederico de Castro. A seca na história do Ceará In: SOUZA, Simone de (Org.). Uma nova história do Ceará. 4. ed. Fortaleza: Edições Demócrito Rocha, p. 76-102, 2015.

OJIMA, Ricardo; COSTA, José Vilton; CALIXTA, Renata Kissya. "Minha vida é andar por esse país...": a emigração recente no semiárido setentrional, políticas sociais e meio ambiente. REMHU - Rev. Interdiscip. Mobil. Hum., Brasília, Ano XXII, n. 43, p. 149-167, jul./dez. 2014.

OLIVEIRA, Ariovaldo Umbelino de. A agricultura camponesa no Brasil. 4. ed. São Paulo: Contexto, 2001.

PONTES, Emílio Tarlis Mendes. Transições paradigmáticas: do combate à seca à convivência com o semiárido, o caso do programa Um Milhão de Cisternas no município de Afogados 
da Ingazeira - PE. Recife: Ed. Universitária da UFPE, 2010.

(Coleção teses e dissertações).

RECH, Daniel. O genocídio no meio de nós. In: CPT. CEPAC.

IBASE. O genocídio do Nordeste (1979-1983). São Paulo: Mandacaru, p. 20-29, 1989.

SANTOS, Milton, 1926-2001. A Natureza do Espaço: Técnica e Tempo, Razão e Emoção. 4. ed. 2. reimpr. São Paulo: Editora da Universidade de São Paulo, 2006.

SOUZA, Luís Eduardo de. Resistência popular ao genocídio In: CPT. CEPAC. IBASE. O genocídio do Nordeste (19791983). São Paulo: Mandacaru, p. 90-114, 1989.

VIANNA, Pedro Costa Guedes. As grandes obras hídricas e as tecnologias sociais hídricas, uma convivência necessária In: MITIDIERO JÚNIOR, Marco Antonio; GARCIA, Maria Franco; _. A questão agrária no século XXI: escalas, dinâmicas e conflitos territoriais. São Paulo: Outras Expressões, p. 405-434, 2015. 